\title{
Impact of Myeloproliferative Neoplasms (MPNs) on Patient Employment and Income: Findings From the Living with MPNs Survey
}

\section{Simon Condliffe}

West Chester University

Jingbo Yu ( $\square$ jyu@incyte.com )

Incyte Corporation

Dilan Paranagama

Incyte Corporation

Shreekant Parasuraman

Incyte Corporation

Research article

Keywords: employment status, income, myeloproliferative neoplasms, patient-reported outcome measures

Posted Date: November 15th, 2019

DOl: https://doi.org/10.21203/rs.2.17364/v1

License: (a) (1) This work is licensed under a Creative Commons Attribution 4.0 International License. Read Full License 


\section{Abstract}

Background The objective of this analysis was to evaluate income loss resulting from disease-related employment changes among patients with myeloproliferative neoplasms (MPNs).

Methods Patients aged 18 to 70 years diagnosed with an MPN were eligible to participate in the online Living with MPNs survey (April-November, 2016). Respondents employed the time of diagnosis were asked questions about changes in employment status related to their MPN and their salaries before and after those changes. Cumulative income loss resulting from disease-related employment changes up to the time of the survey was calculated based on the timing of changes in employment and salary, which was reported in inflation-adjusted 2018 US dollars.

Results Among 904 patients with an MPN who responded to the survey, 299 were employed at the time of MPN diagnosis and reported $\geq 1$ disease-related employment change. For nearly half (144/299 [48.2\%]) of employed patients who reported a change in employment status, the first change occurred within 1 year of diagnosis, and most (229/299 [76.6\%]) had $\geq 1$ change within 2 years. Employment status changes and the associated impact on income were greatest among patients who took early retirement $(\$ 517,866$ lost income), followed by those who took medical disability leave $(\$ 289,910)$ or left a job because of their disease $(\$ 257,178)$.

Conclusions Disease-related employment changes contributed to considerable income loss among patients with MPNs. Similar to other chronic conditions, potential exists for disease-related employment changes and income loss among patients with MPNs that should be considered during disease management.

\section{Background}

Myeloproliferative neoplasms (MPNs), including myelofibrosis (MF), polycythemia vera (PV), and essential thrombocythemia (ET), are chronic hematologic malignancies that are associated with reduced survival compared with the age- and sex-matched general population [1,2]. Patients with an MPN are at heightened risk for thrombosis and transformation to acute myeloid leukemia [3, 4]. In addition, they may experience a broad range of symptoms $[5,6]$ that compromise daily functioning and quality of life [5-7]. In the MPN Landmark survey of patients in the United States, fatigue was the most commonly reported symptom in all 3 MPN subtypes (MF, 80\%; PV, 73\%; ET, 71\%) [5]. Abdominal pain and night sweats were experienced by approximately half of patients with $\mathrm{MF}(53 \%$ and $51 \%$, respectively) and were also common in PV (35\% and 45\%) and ET (31\% and 38\%) [5]. Other common symptoms ( $20 \%$ of patients for each MPN) included bone pain, pruritus, early satiety, and concentration problems [5].

In addition to symptom-related reduction in quality of life [5-7], patients with an MPN also experience work impairments and decreased productivity $[5,7,8]$. In the Living with MPNs survey, a cross-sectional online survey of patients with an MPN living in the United States, approximately half (50.5\%) of employed respondents reported $\geq 1$ change in employment status related to their diagnosis [8]. The most commonly 
cited changes in work status included "left a job" (30.2\%), "went on medical disability" (24.8\%), and "had reductions in work hours for $\geq 3$ months" (21.8\%) [8]. More than half of respondents (54.4\%) also reported limitations to their career opportunities due to their diagnosis [8].

Patients with chronic or malignant diseases often face economic hardship [9-11]. A longitudinal US survey of cancer survivors showed that income decreased by up to $40 \%$ by the second year after diagnosis and remained low up to 5 years after diagnosis [12]. Furthermore, findings from patientreported outcomes studies in patients with cancer show significant self-perceived financial distress and include reports of financial reductions to health-related areas in attempts to alleviate financial burden, as well as accumulation of debt [13]. Similarly, substantial income loss has been reported for other chronic diseases with high symptom burden, such as Parkinson's disease and arthritis $[14,15]$. This analysis from the Living with MPNs survey evaluated income loss associated with disease-related employment changes among patients with an MPN in the United States.

\section{Methods}

\section{Study Design and Patients}

The Living with MPNs survey was a cross-sectional online questionnaire administered between April and November 2016 [8]. Patients aged 18 to 70 years; diagnosed with MF, PV, or ET; and living in the United States were eligible to participate. Participants were recruited through posts on MPN-focused social media (eg, patient group Facebook pages); emails and postcards sent by MPN groups; posts on patient advocacy websites; banner or text advertisements on selected medical websites, Google, and Facebook; and postcards sent to the offices of hematologists and oncologists for distribution. The study was approved by the Quorum Review Institutional Review Board. Patients provided informed consent before responding to the survey and were offered an optional \$25 incentive for completing the survey. Only questionnaires with answers to all eligible survey questions were considered for the analysis.

\section{Survey Instruments}

Details of the Living with MPNs survey have been previously described $[8,16,17]$. In brief, the questionnaire consisted of approximately 100 questions related to MPN diagnosis; disease-related history; changes since diagnosis in employment status, work productivity, and daily activities; MPNrelated symptoms; and functional status. Respondents who were employed the time of MPN diagnosis were asked an additional set of questions about disease-related changes in employment status and salary income before and after those employment changes. The survey was designed to take approximately 30 minutes to complete.

\section{Statistical Analyses}


Cumulative income loss as a result of disease-related employment changes up to the time of the survey was calculated based on the timing of changes in employment and salary then adjusted for inflation to 2018 US dollars using the Bureau of Labor Statistics Consumer Price Index. For an individual (I), inflationadjusted income loss was summed over the duration of employment status change as follows:

[Due to technical limitations, the formula could not be displayed here. Please see the supplementary files section to access the formula.]

where time $(t)=0$ for the year of the change in employment status, and $t=n$ for either the survey year or the year when the employment change ended. The summed losses were averaged across individuals by type of employment status change. As an example for income loss determination, assume 2 individuals (persons A and B) left their jobs because of their MPN diagnoses. One was earning $\$ 50,000$ per year and left in 2014 , the other earned $\$ 75,000$ per year and left in 2015 . Their annual lost income was adjusted to 2018 dollars, summed for the duration until the time of the survey (through 2016), and then averaged across individuals experiencing the same type of change in employment status (Table 1).

<<Insert Table 1 here >

Survey response options regarding salary were presented in multiple-choice format, with salary ranges in $\$ 5000$ intervals; the middle of each provided range was used to calculate population means in the analysis. A nationally representative population in the Medical Expenditure Panel Survey (MEPS) database (2014-2015) was used as a comparator (ie, general US population) for the prevalence of leaving a job and taking early retirement. The MEPS is a set of large-scale surveys of families and individuals, their medical providers, and employers across the United States that provides a nationally representative dataset on the cost and use of healthcare and health insurance [18]. Formal statistical analyses for significance were not conducted.

\section{Results}

\section{Demographics, Employment Status, and Disease Characteristics of Employed Respondents}

The Living with MPNs survey included 904 respondents, 592 (65\%) of whom were employed at the time of MPN diagnosis. Detailed patient demographics and disease characteristics among employed respondents of the Living with MPNs survey have been described previously [8]. Briefly, 174 (29.4\%), 248 (41.9\%), and 170 (28.7\%) employed respondents were diagnosed with MF, PV, and ET, respectively. The mean age of respondents employed at diagnosis was 54.0 years, $70.6 \%$ were female, $72.3 \%$ were married or had domestic partners, and most (81.3\%) were employed full-time at diagnosis (Table 2). The average time from MPN diagnosis to survey administration was 6.1 years (MF, 4.6; PV, 6.9; ET, 6.3). 


\section{Changes in Employment Status}

Two-hundred ninety-nine of 592 employed respondents (50.5\%) reported $\geq 1$ change in employment due to their diagnosis, with $34.5 \%$ (204/592) of respondents reporting $\geq 2$ employment changes since diagnosis and $21.5 \%(127 / 592)$ reporting $\geq 3$ changes (Table 3). For nearly half (144/299 [48.2\%]) of respondents who reported a change in employment status, the first change occurred within 1 year of diagnosis (MF, 54.4\%; PV, 41.2\%; ET, 50.0\%), and most (229/299 [76.6\%]) had $\geq 1$ change within 2 years of diagnosis (MF, 87.7\%; PV, 65.5\%; ET, 77.3\%; Figure 1). The time between MPN diagnosis and employment status change varied by the type of change. For example, among patients who took medical disability leave, 72.8\% (107/147) did so within 2 years of diagnosis (MF, 80.3\%; PV, 63.6\%; ET, 73.1\%); in contrast, among those who reported reassignment to a lower-paying job, only $55.7 \%$ (34/61) were reassigned over the same 2-year period (MF, 70.6\%; PV 43.3\%; ET, 64.3\%; Table 4). The mean duration of employment change was approximately 3 years, and patients who took early retirement did so a mean of 8.5 years ahead of schedule (Table 5 ).

<<Insert Table 3 here>>

<<Insert Table 4 here >>

<<Insert Table 5 here>>

Among respondents aged 45 to 64 years at the time of completing the survey ( $n=383), 18.8 \%$ reported retiring early as a result of their disease. In comparison, according to nationally representative data from the MEPS, only $7.8 \%$ of individuals in the same age range in excellent or very good health and $9.2 \%$ of individuals in poor health retired earlier than planned (longitudinal dataset 2014-2015; Figure 2) [18]. Additionally, 30.5\% (117/383) of respondents aged 45 to 64 years from the Living with MPNs survey reported leaving a job because of their disease, compared with $5.5 \%$ and $16.4 \%$ of MEPS individuals (4564 years) in excellent/very good health and poor health, respectively, who were working at the start of 2014 but not by the end of 2015 .

\section{Impact of Changes in Employment Status on Income}

Employment status changes and the associated impact on income were greatest among respondents who took early retirement (18.4\% [109/592] of patients; $\$ 517,866$ lost income for all MPNs), followed by those who went on medical disability leave $(24.8 \%$ [147/592]; $\$ 289,910)$ or left a job because of their disease (30.2\% [179/592]; $\$ 257,178$; Figure 3). Income losses were also reported by respondents who changed from full-time to part-time employment (15.0\% [89/592] of patients; $\$ 112,164$ lost income for all MPNs), were reassigned to a lower paying job because of their disease $(10.3 \%$ [61/592]; $\$ 75,377)$, or had reduced hours (21.8\% [129/592]; \$65,878; Figure 3).

\section{Discussion}


Approximately half of the patients with an MPN who participated in the Living with MPNs survey experienced changes in employment status because of their disease. Among employed patients who had a change in employment status, nearly half experienced that change within 1 year of MPN diagnosis, with time to change varying by type of employment change. Early retirement was taken by $18 \%$ of patients, occurring an average of 8.5 years earlier than planned because of their disease; $30 \%$ of patients left a job and $25 \%$ took medical disability leave. Respondents aged 45 to 64 years were more likely to take early retirement or leave a job compared with the general US population. Employment status changes and the associated losses in income were greatest among patients who took early retirement, followed by those who went on medical disability leave or left a job owing to their disease.

Findings from this study suggest that patients with an MPN face significant financial hardships as a result of their disease and support previous patient-reported data. In the US MPN Landmark survey, many employed respondents reported lost productivity from reduced work hours (30\%-59\%), calling in sick to work (19\%-29\% with $\geq 1$ sick day in the preceding 30 days), terminating their job (voluntarily, $11 \%-31 \%$; involuntarily, $4 \%-5 \%)$, taking medical disability $(7 \%-28 \%)$, or early retirement $(14 \%-30 \%)$ [5]. The impact of symptom burden on overall health and productivity was also assessed in the US MPN Landmark survey. Patients with MF had the highest mean MPN Symptom Assessment Form total symptom score (MPN-SAF TSS; 21.2 vs 17.4 for PV and 14.8 for ET) and were more likely to report that their MPN symptoms interfered with daily activities "a great deal" $(21 \%)$ compared with patients with PV $(10 \%)$ or ET (7\%) [5]. In agreement with these findings, respondents in the Living with MPNs survey with MF were the most likely to have an employment change and to take medical disability leave. A previous analysis of the Living with MPNs survey indicated that patients who reported taking medical disability leave had more frequent and severe symptoms and functional impairments compared with those who reported no changes in employment status [16]. Among patients who took medical disability leave, no differences in MPN-SAF TSS were observed across MPN subtypes. The impact of symptom burden on other types of employment changes was not assessed [16]. Finally, in a separate analysis from the Living with MPNs survey on employment status and work productivity, patients with ET most often reported having their wages or salary "not at all" affected by their MPN (63.5\% vs $47.7 \%$ for MF and $56.9 \%$ for PV) [8]. This is noteworthy in the context of the current analysis, which reported that patients diagnosed with ET typically incurred the greatest income losses in inflation-adjusted 2018 US dollars. These data may reflect the longer duration in select employment changes (eg, leaving a job, taking medical disability leave, switching from full-time to part-time work, reassignment to a lower-paying job) among patients with ET relative to patients with MF or PV. The longer duration of these employment changes in combination with income at the time of employment change likely contributes to the greater income loss observed among respondents with ET.

The income loss observed among patients with an MPN in this study was a function of initial income and duration of employment change. Similar earnings losses, particularly resulting from early retirement, have been observed for patients with cancer or other chronic diseases. Longitudinal survey data from a nationally representative observational study of employed patients with various cancers showed $a>20 \%$ decline in total family income 2 to 3 years after diagnosis (median income $\$ 31,8002$ years before 
diagnosis vs $\$ 27,4702$ years after diagnosis) and a $40 \%$ reduction in individual labor market earnings by the second year [12]. Among patients with Parkinson's disease, simulated lifetime earnings losses over the period from age 40 to 79 years were $\$ 569,393$ for patients diagnosed at 45 years of age and $\$ 188,590$ for those diagnosed at 55 years of age; high rates of early retirement were also observed in these patients [14]. In an international survey of working-age patients between the ages of 45 and 67 years with chronic obstructive pulmonary disease, average lifetime earnings losses due to early retirement were $\$ 316,000$ [19]. The American Diabetes Association estimated that, in 2012, patients who left the workforce early because of diabetes incurred an average daily earnings loss of $\$ 166$ per person [11]. Finally, based on analysis of the US MEPS database, national arthritis-attributable earnings losses among patients aged 18 to 64 years were $\$ 163.7$ billion in 2013; the per-patient arthritis-related income loss was estimated at $\$ 4040$ for the same year [15]. Thus, similar to other chronic conditions, there is considerable potential for disease-related employment change and income loss that should be considered in the management of patients diagnosed with an MPN.

Noteworthy limitations of the current study include a potential selection bias regarding who participated in the survey, as participant recruitment was limited to patients who could be reached via social media, email, postcard mailings to patients' homes and doctors' offices, and Google advertisements. The impact of multiple employment changes on income loss was not assessed because of the many combinations of employment changes and the small number of patients in each combination. Finally, for respondents who did not report an end of their job change, the time of survey was used as the end time of the job change, which may underestimate income loss for these patients.

\section{Conclusions}

Considerable income loss resulting from disease-related employment changes was observed in patients with an MPN living in the United States, which should be taken into consideration during the management of patients diagnosed with an MPN.

\section{List Of Abbreviations}

ETessential thrombocythemia

MDLmedical disability leave

MEPSMedical Expenditure Panel Survey

MFmyelofibrosis

MPNmyeloproliferative neoplasm

MPN-SAF TSSMyeloproliferative Neoplasm Symptom Assessment Form total symptom score

NAnot applicable 


\section{Declarations}

\section{Ethics approval and consent to participate}

The study was approved by the Quorum Review Institutional Review Board and all procedures were conducted in accordance with the principles embodied by the 1964 Declaration of Helsinki and all of its subsequent revisions. Informed patient consent was obtained from all patients electronically before survey completion.

\section{Consent for publication}

Not applicable.

\section{Availability of data and materials}

The datasets used and/or analyzed during the current study are available from the corresponding author on reasonable request.

\section{Competing interests}

SC is a consultant for Incyte Corporation. JY, DP, and SP are employees and stockholders of Incyte Corporation.

\section{Funding}

Incyte Corporation (Wilmington, DE) funded this study and was involved in the design of the study; collection, analysis, and interpretation of data; and in writing the manuscript.

\section{Authors' contributions}

All authors were involved in the study design and the analysis and interpretation of the data. All authors read and approved the final manuscript.

\section{ACKNOWLEDGMENTS}

Writing assistance was provided by Jane Kovalevich, $\mathrm{PhD}$, at Complete Healthcare Communications, LLC (North Wales, PA), a CHC Group company, and was funded by Incyte Corporation (Wilmington, DE). 


\section{References}

1.Hultcrantz M, Kristinsson SY, Andersson TM, Landgren O, Eloranta S, Derolf AR, Dickman PW, Björkholm M: Patterns of survival among patients with myeloproliferative neoplasms diagnosed in Sweden from 1973 to 2008: a population-based study. J Clin Oncol 2012, 30(24):2995-3001.

2.Price GL, Davis KL, Karve S, Pohl G, Walgren RA: Survival patterns in United States (US) Medicare enrollees with non-CML myeloproliferative neoplasms (MPN). PLoS One 2014, 9(3):e90299.

3.Brunner AM, Hobbs G, Jalbut MM, Neuberg DS, Fathi AT: A population-based analysis of second malignancies among patients with myeloproliferative neoplasms in the SEER database. Leuk Lymphoma 2015:1-4.

4. Hultcrantz M, Bjorkholm M, Dickman PW, Landgren O, Derolf AR, Kristinsson SY, Andersson TML: Risk for arterial and venous thrombosis in patients with myeloproliferative neoplasms: a population-based cohort study. Ann Intern Med 2018, 168(5):317-325.

5.Mesa R, Miller CB, Thyne M, Mangan J, Goldberger S, Fazal S, Ma X, Wilson W, Paranagama DC, Dubinski DG et al: Myeloproliferative neoplasms (MPNs) have a significant impact on patients' overall health and productivity: the MPN Landmark survey. BMC Cancer 2016, 16:167.

6.Emanuel RM, Dueck AC, Geyer HL, Kiladjian JJ, Slot S, Zweegman S, te Boekhorst PAW, Commandeur S, Schouten HC, Sackmann F et al: Myeloproliferative Neoplasm (MPN) Symptom Assessment Form Total Symptom Score: prospective international assessment of an abbreviated symptom burden scoring system among patients with MPNs. J Clin Oncol 2012, 30(33):4098-4103.

7.Harrison CN, Koschmieder S, Foltz L, Guglielmelli P, Flindt T, Koehler M, Mathias J, Komatsu N, Boothroyd RN, Spierer A et al: The impact of myeloproliferative neoplasms (MPNs) on patient quality of life and productivity: results from the international MPN Landmark survey. Ann Hematol 2017, 96(10):1653-1665.

8.Yu J, Parasuraman S, Paranagama D, Bai A, Naim A, Dubinski D, Mesa R: Impact of myeloproliferative neoplasms on patients' employment status and work productivity in the United States: results from the Living With MPNs survey. BMC Cancer 2018, 18(1):420.

9.NCBI Bookshelf. National Library of Medicine, National Institutes of Health: Chapter 1: The psychosocial needs of cancer patients. In: Cancer Care for the Whole Patient: Meeting Psychosocial Health Needs. edn. Edited by Adler NE, Page AEK. Washington DC: National Academics Press; 2008.

10.Heidenreich PA, Trogdon JG, Khavjou OA, Butler J, Dracup K, Ezekowitz MD, Finkelstein EA, Hong Y, Johnston SC, Khera A et al: Forecasting the future of cardiovascular disease in the United States: a policy statement from the American Heart Association. Circulation 2011, 123(8):933-944. 
11.American Diabetes Association: Economic costs of diabetes in the U.S. in 2012. Diabetes Care 2013, 36(4):1033-1046.

12.Zajacova A, Dowd JB, Schoeni RF, Wallace RB: Employment and income losses among cancer survivors: estimates from a national longitudinal survey of American families. Cancer 2015, 121(24):4425-4432.

13.Catt S, Starkings R, Shilling V, Fallowfield L: Patient-reported outcome measures of the impact of cancer on patients' everyday lives: a systematic review. J Cancer Surviv 2017, 11(2):211-232.

14.Johnson S, Davis M, Kaltenboeck A, Birnbaum H, Grubb E, Tarrants M, Siderowf A: Early retirement and income loss in patients with early and advanced Parkinson's disease. Appl Health Econ Health Policy 2011, 9(6):367-376.

15.Murphy LB, Cisternas MG, Pasta DJ, Helmick CG, Yelin EH: Medical expenditures and earnings losses among US adults with arthritis in 2013. Arthritis Care Res (Hoboken) 2018, 70(6):869-876.

16.Yu J, Paranagama D, Geyer HL, Parasuraman S, Mesa R: Relationship between symptom burden and disability leave among patients with myeloproliferative neoplasms (MPNs): findings from the Living with MPN patient survey. Ann Hematol 2019, 98(5):1119-1125.

17.Paranagama D, Parasuraman S, Yu J, Lyle L, Mesa R: Impact on caregivers of patients with myeloproliferative neoplasms (MPNs) in the United States: results from the Living With MPNs survey. Int Arch Nurs Health Care 2018, 4:108.

18.Medical Expenditure Panel Survey [https://meps.ahrq.gov/mepsweb/]

19.Fletcher MJ, Upton J, Taylor-Fishwick J, Buist SA, Jenkins C, Hutton J, Barnes N, Van Der Molen T, Walsh JW, Jones $\mathrm{P}$ et al: COPD uncovered: an international survey on the impact of chronic obstructive pulmonary disease [COPD] on a working age population. BMC Public Health 2011, 11:612.

\section{Tables}

\section{Table 1. Example Scenario for Income Loss Determination}

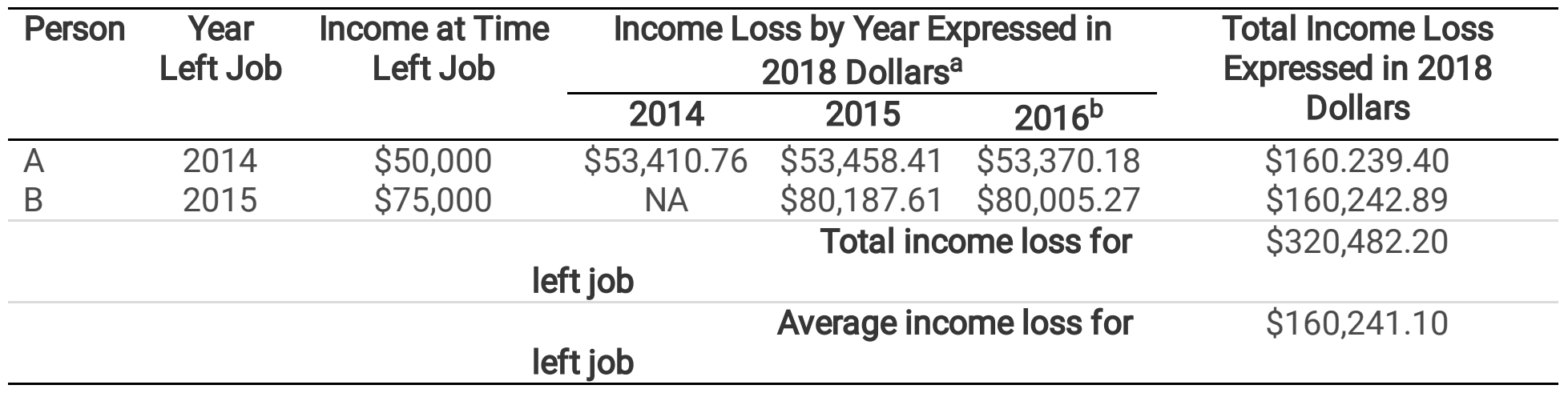


NA, not applicable.

a Consumer Price Index is used to inflate annual lost income to 2018 dollars. Inflation adjustments are as follows: $2014=1.068215 ; 2015=1.069168 ; 2016=1.067404$.

b Year of survey; for respondents who did not report an end of their job change, the time of survey was used as the end time of the job change.

\section{Table 2. Patient-Reported Characteristics of Survey Respondents Employed at the Time of Diagnosis}

\begin{tabular}{lcccc}
\hline Characteristic & $\begin{array}{c}\text { MF } \\
(\mathrm{n}=174)\end{array}$ & $\begin{array}{c}\text { PV } \\
(\mathrm{n}=248)\end{array}$ & $\begin{array}{c}\mathrm{ET} \\
(\mathrm{n}=170)\end{array}$ & $\begin{array}{c}\text { All MPNs } \\
(\mathrm{N}=592)\end{array}$ \\
\hline Age, mean (SD), y & $57.5(9.8)$ & $54.5(9.1)$ & $49.6(12.2)$ & $54.0(10.7)$ \\
Female, $\mathrm{n}(\%)$ & $106(60.9)$ & $173(69.8)$ & $139(81.8)$ & $418(70.6)$ \\
\hline Employment status at MPN diagnosis, $\mathrm{n}(\%)$ & & & & \\
\hline$\quad$ Full-time ( $\geq 40 \mathrm{~h} / \mathrm{wk})$ & $139(79.9)$ & $203(81.9)$ & $139(81.8)$ & $481(81.3)$ \\
\hline$\quad$ Part-time (<40 h/wk) & $35(20.1)$ & $45(18.1)$ & $31(18.2)$ & $111(18.8)$ \\
\hline Time since MPN diagnosis, mean (SD), y & $4.6(4.7)$ & $6.9(7.2)$ & $6.3(6.4)$ & $6.1(6.4)$ \\
\hline
\end{tabular}

ET, essential thrombocythemia; MF, myelofibrosis, MPN, myeloproliferative neoplasm; PV, polycythemia vera.

\section{Table 3. Number of Employment Changes by Condition Among Respondents Employed at MPN Diagnosis}

\begin{tabular}{lcccc}
\hline Employment Changes, $\mathbf{n}(\%)$ & MF & PV & ET & All MPNs \\
& $(\mathbf{n = 1 7 4 )}$ & $(\mathbf{n}=\mathbf{2 4 8})$ & $(\mathbf{n}=\mathbf{1 7 0})$ & $(\mathbf{N}=\mathbf{5 9 2})$ \\
\hline$\geq 1$ & $114(65.5)$ & $119(48.0)$ & $66(38.8)$ & $299(50.5)$ \\
$\geq 2$ & $88(50.6)$ & $78(31.5)$ & $38(22.4)$ & $204(34.5)$ \\
$\geq 3$ & $55(31.6)$ & $46(18.5)$ & $26(15.3)$ & $127(21.5)$ \\
\hline
\end{tabular}

ET, essential thrombocythemia; MF, myelofibrosis; MPN, myeloproliferative neoplasm; PV, polycythemia vera.

\section{Table 4. Time to Change in Employment by Condition and Type of Employment Change}




\begin{tabular}{|c|c|c|c|c|}
\hline Employment Change, \% & $\begin{array}{c}\text { MF } \\
(n=174)\end{array}$ & $\begin{array}{c}P V \\
(n=248)\end{array}$ & $\begin{array}{c}\text { ET } \\
(n=170)\end{array}$ & $\begin{array}{l}\text { All MPNs } \\
(\mathrm{N}=592)\end{array}$ \\
\hline Left job & $\mathrm{n}=80$ & $\mathrm{n}=66$ & $\mathrm{n}=33$ & $n=179$ \\
\hline$<1 \mathrm{y}$ & 43.8 & 37.9 & 42.4 & 41.3 \\
\hline $1-2 y$ & 35.0 & 25.8 & 24.2 & 29.6 \\
\hline $3-5 y$ & 12.5 & 13.6 & 9.1 & 12.3 \\
\hline$\geq 6 y$ & 8.8 & 22.7 & 24.2 & 16.8 \\
\hline Took MDL & $n=66$ & $n=55$ & $n=26$ & $n=147$ \\
\hline$<1 \mathrm{y}$ & 42.4 & 43.6 & 61.5 & 46.3 \\
\hline $1-2 y$ & 37.9 & 20.0 & 11.5 & 26.5 \\
\hline $3-5 y$ & 9.1 & 25.5 & 15.4 & 16.3 \\
\hline$\geq 6 \mathrm{y}$ & 10.6 & 10.9 & 11.5 & 10.9 \\
\hline Reduced hours & $n=43$ & $n=54$ & $n=32$ & $n=129$ \\
\hline$<1 \mathrm{y}$ & 55.8 & 35.2 & 46.9 & 45.0 \\
\hline $1-2 y$ & 30.2 & 29.6 & 21.9 & 27.9 \\
\hline $3-5 y$ & 14.0 & 14.8 & 9.4 & 13.2 \\
\hline$\geq 6 y$ & 0 & 20.4 & 21.9 & 14.0 \\
\hline Early retirement & $n=48$ & $n=41$ & $n=20$ & $n=109$ \\
\hline$<1 \mathrm{y}$ & 35.4 & 22.0 & 40.0 & 31.2 \\
\hline $1-2 y$ & 33.3 & 19.5 & 10.0 & 23.9 \\
\hline $3-5 y$ & 18.8 & 34.1 & 20.0 & 24.8 \\
\hline$\geq 6 y$ & 12.5 & 24.4 & 30.0 & 20.2 \\
\hline Full-time to part-time hours & $n=28$ & $n=35$ & $n=26$ & $n=89$ \\
\hline$<1 \mathrm{y}$ & 42.9 & 25.7 & 26.9 & 31.5 \\
\hline $1-2 y$ & 28.6 & 34.3 & 30.8 & 31.5 \\
\hline $3-5 y$ & 28.6 & 14.3 & 23.1 & 21.3 \\
\hline$\geq 6 \mathrm{y}$ & 0 & 25.7 & 19.2 & 15.7 \\
\hline Reassignment & $n=17$ & $n=30$ & $\mathrm{n}=14$ & $n=61$ \\
\hline$<1 \mathrm{y}$ & 52.9 & 33.3 & 64.3 & 45.9 \\
\hline $1-2 y$ & 17.6 & 10.0 & 0 & 9.8 \\
\hline $3-5 y$ & 17.6 & 20.0 & 7.1 & 16.4 \\
\hline$\geq 6 y$ & 11.8 & 36.7 & 28.6 & 27.9 \\
\hline
\end{tabular}

ET, essential thrombocythemia; MDL, medical disability leave; MF, myelofibrosis; MPN, myeloproliferative neoplasm; PV, polycythemia vera.

\section{Table 5. Mean Duration of Employment Change by Condition}




\begin{tabular}{|c|c|c|c|c|}
\hline Employment Change, $\mathrm{n}(\%)$ & $\begin{array}{c}\text { MF } \\
(n=174)\end{array}$ & $\begin{array}{c}\text { PV } \\
(n=248)\end{array}$ & $\begin{array}{c}\text { ET } \\
(n=170)\end{array}$ & $\begin{array}{l}\text { All MPNs } \\
(\mathrm{N}=592)\end{array}$ \\
\hline Left job & $80(46.0)$ & $66(26.6)$ & $33(19.4)$ & $179(30.2)$ \\
\hline Gap between jobs, ${ }^{a} y$ & 2.9 & 3.3 & 4.3 & 3.3 \\
\hline Took MDL & $66(37.9)$ & $55(22.2)$ & $26(15.3)$ & $147(24.8)$ \\
\hline Length of leave, ${ }^{a} y$ & 3.0 & 3.8 & 4.3 & 3.5 \\
\hline Reduced hours & $43(24.7)$ & $54(21.8)$ & $32(18.8)$ & $129(21.8)$ \\
\hline Length of change, ${ }^{a} y$ & 3.5 & 2.9 & 1.3 & 2.7 \\
\hline Early retirement & $48(27.6)$ & $41(16.5)$ & $20(11.8)$ & $109(18.4)$ \\
\hline Years in advance of planned retirement & 7.7 & 9.7 & 7.8 & 8.5 \\
\hline Full-time to part-time & $28(16.1)$ & $35(14.1)$ & $26(15.3)$ & $89(15.0)$ \\
\hline Length of change, ${ }^{a} y$ & 3.6 & 2.6 & 4.3 & 3.4 \\
\hline Reassigned to a lower-paying job & $17(9.8)$ & $30(12.1)$ & $14(8.2)$ & $61(10.3)$ \\
\hline Length of change, ${ }^{a} y$ & 3.3 & 2.4 & 4.3 & 3.1 \\
\hline
\end{tabular}

ET, essential thrombocythemia; MDL, medical disability leave; MF, myelofibrosis; MPN, myeloproliferative neoplasm; PV, polycythemia vera.

a Time from start to end of event or to date of survey, whichever occurred first.

\section{Figures}

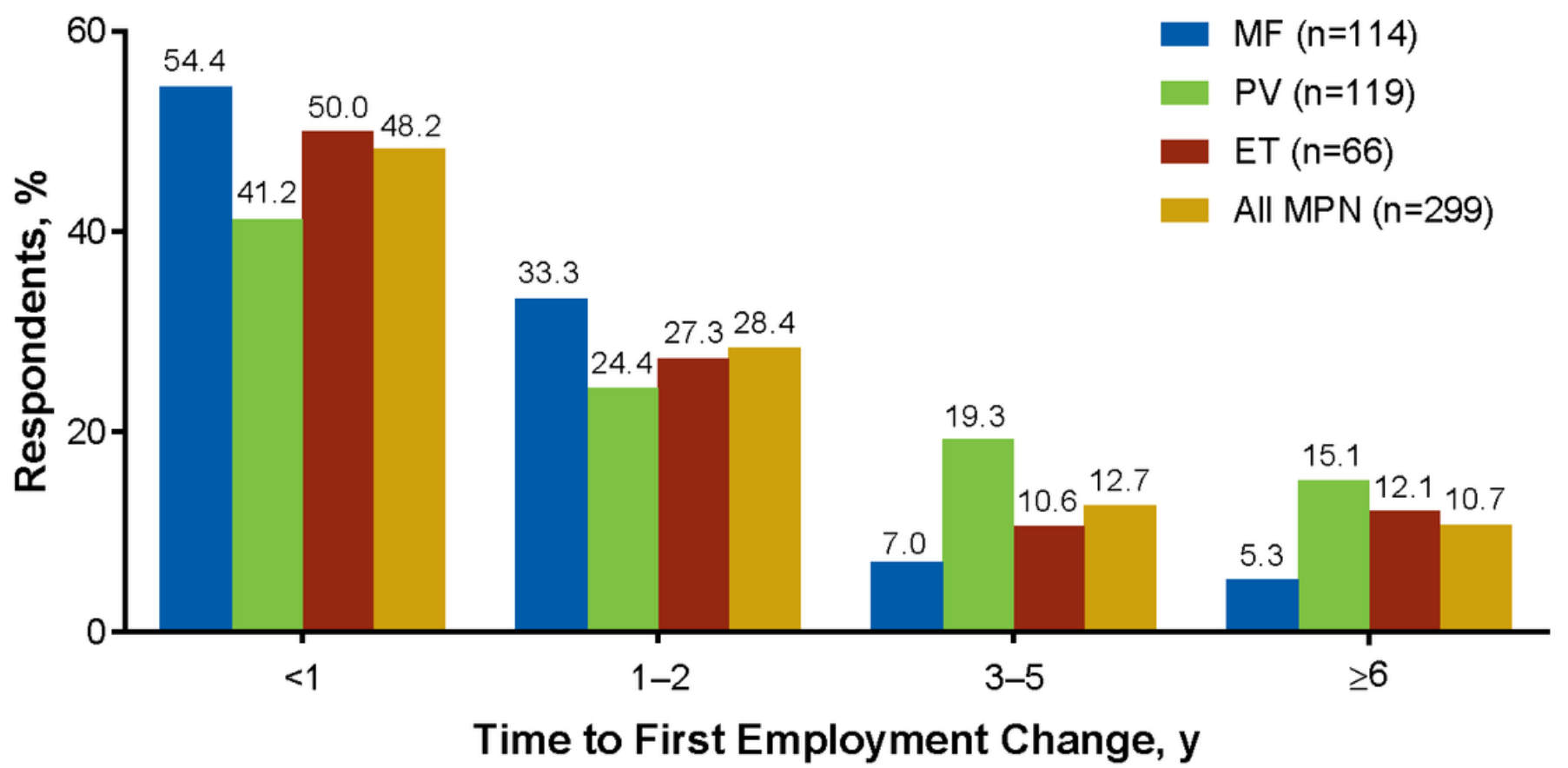

Figure 1 
Time to First Employment Change From Diagnosis by Condition. Graph includes all patients employed at the time of MPN diagnosis with $\geq 1$ disease-related employment change $(n=299)$. ET, essential thrombocythemia; MF, myelofibrosis; MPN, myeloproliferative neoplasm; PV, polycythemia vera.

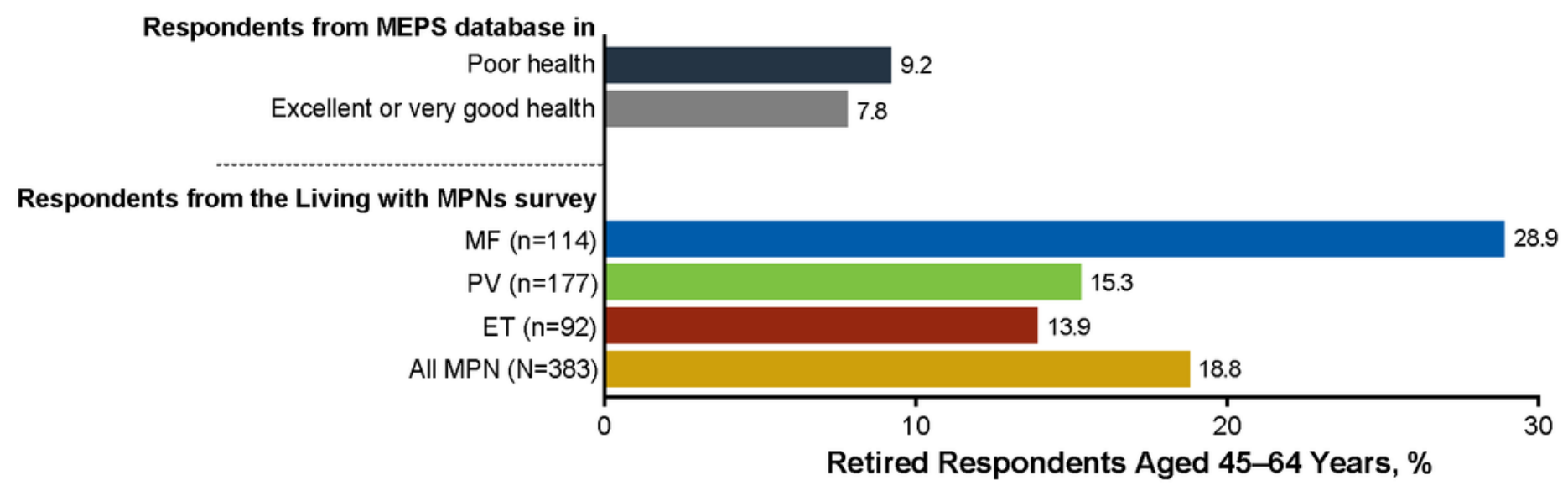

Figure 2

Percentage of Retired Respondents Aged 45-64 Years. Graph includes all respondents who were 45-64 years of age at the time of the survey, regardless of employment change status $(n=383)$. ET, essential thrombocythemia; MEPS, Medical Expenditure Panel Survey; MF, myelofibrosis; MPN, myeloproliferative neoplasm; PV, polycythemia vera.

Income Loss, Mean

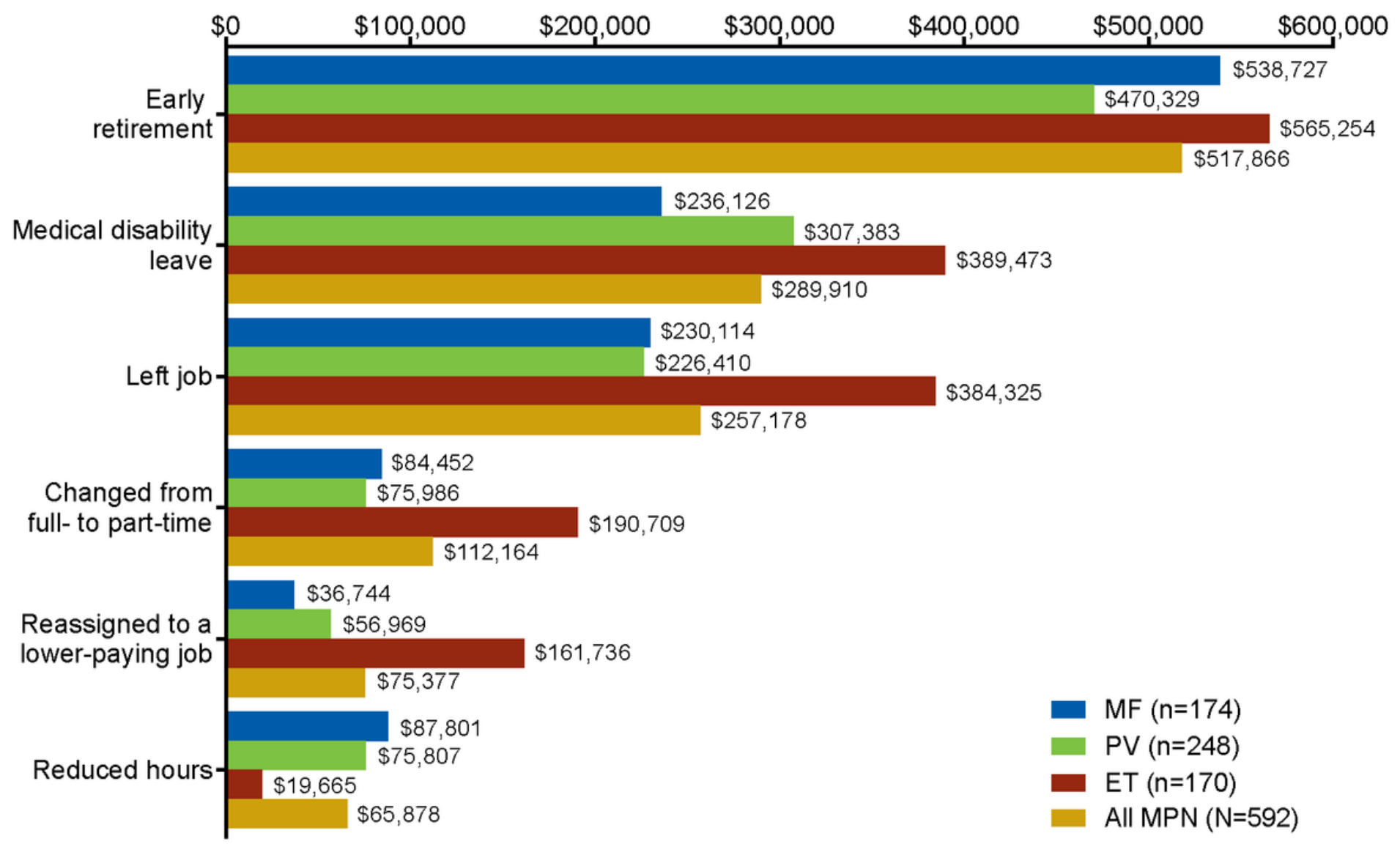




\section{Figure 3}

Income Loss Due to Changes in Employment Status. Graph includes all respondents who were employed at the time of their MPN diagnosis ( $n=592)$. For respondents who did not report an end of their job change, the time of survey was used as the end time of the job change. ET, essential thrombocythemia; MF, myelofibrosis; MPN, myeloproliferative neoplasm; PV, polycythemia vera.

\section{Supplementary Files}

This is a list of supplementary files associated with this preprint. Click to download.

- Methodsformula.docx 